\title{
JACK LONDON Y HORACIO QUIROGA
}

\author{
POR \\ EVELIO ECHEVARRIA \\ Colorado State University
}

Pocos autores han sido han honrados en reconocer la influencia de sus maestros como el cuentista uruguayo-argentino Horacio Quiroga, quien mencionó la de Edgar Allan Poe, Antón Chejov, Guy de Maupassant y Rudyard Kipling ${ }^{1}$. Cosa curiosa, aunque la influencia del norteamericano Jack London es evidente en sus escritos, nunca la mencionó. Ni tampoco mencionó la de Dostoyevski y Joseph Conrad, que uno de sus críticos señaló en un estudio ${ }^{2}$. Pero deberá reconocerse que las relaciones literarias interamericanas no han sido estudiadas apropiadamente. La influencia de London sobre los narradores del criollismo hispanoamericano todavía espera el estudio que se merece. Al crítico Arnold Chapman debemos un análisis sobre la acogida que tuvo la narrativa norteamericana en la América española; su estudio contiene una parte específica sobre la posible influencia de London y de James Oliver Curwood sobre los narradores hispanoamericanos, especialmente los chilenos ${ }^{3}$. En otro estudio, el mismo Chapman analizó el notable paralelo que existe entre London y Horacio Quiroga ${ }^{4}$. Algunos investigadores tocaron a veces el tema de estas influencias, pero en forma muy somera ${ }^{5}$. El propósito de la presente colaboración es reforzar la opinión de aquellos críticos, ofreciendo también algunos casos comparativos más.

1 Pedro Orgambide, Horacio Quiroga. El hombre y su obra (Buenos Aires, Stilcograf, 1954), pp. 130-5.

2 Orgambide, loc. cit.

3 Arnold G. Chapman, The Spanish American reception of the United States fiction. 1920-1940 (Berkeley, University of California Press, 1966).

4 Arnold G. Chapman, «Between fire and ice: a theme in Jack London and Horacio Quiroga», Symposium, XXIV, 1 (1970), pp. 17-25.

5 Ernesto Montenegro, «Horacio Quiroga: a literary kin of Rudyard Kipling 


\section{BIOGRAFÍAS PARALELAS}

El notable caso de edos biografías paralelas, ya señalado por Chapman, es siempre la mejor introducción para un estudio de este tema:

London was stocky and blue-eyed and born in San Francisco, California; Horacio Quiroga was light and dark-eyed and born in Salto, Uruguay; they had in common a demonic restlessness that drove them in a constant attempt to find themselves. Writing seemed the only way of survival, and for this they studied their craft. They tried other livelihoods, but their business ventures failed... they went after women and fell in love terrifyingly, but there was difficulty, and their marriages broke. Part of the trouble was their absurd dream of taking a mate away, out of sickening civilization, into a wilderness home. London had a fantassy of a hearthside in the Valley of the Moon, Quiroga of a cottage in San Ignacio; but neither attained the domestic bliss... Savage nature had made them writers; they had been galvanized by their first encounter with it, London in 1897 on the Klondike, Quiroga in 1903 on the Paraná... they easily accepted the Darwinian theory of survival, by which success or failure of the body was a valid criterion, perhaps the only one. And when each man came to a point when his body no longer supported the wild race of vitality, he put an end to life. They both died from self-administered doses of chemical compounds - London by morphine in 1917, Quiroga by cyanide in $1937 \ldots{ }^{6}$

El mismo autor señaló entonces (1970) la necesidad de una bien documentada biografía de Quiroga, la que aún no ha aparecido, aunque sí podemos contar, por ahora, con una bibliografía general del cuentis$\mathrm{ta}^{7}$. Una investigación de sus publicaciones y de su epistolario, como también alguna noticia sobre el inventario de su biblioteca, podría revelarnos sus opiniones sobre el arte de Jack London, al que sin duda debió haber leído, pues la aparición de ciertos temas y motivos londonianos en algunos cuentos de Quiroga es bastante evidente, como se verá a continuación.

Debe señalarse que tanto London como Quiroga pertenecieron a la misma escuela literaria: el naturalismo. Se ha hallado en los cuentos

and Jack London», The New York Times Book Review, 25 de octubre de 1925, p. 10.

6 Chapman, «Between fire and ice...», op. cit., pp. 23-4.

7 Walter Rela, Horacio Quiroga. Repertorio bibliográfico anotado. 1897-1971 (Buenos Aires, Casa Pardo, 1972). 
de animales de Quiroga influencia muy clara del victoriano inglés Rudyard Kipling, influencia que, por lo demás, Quiroga mismo reconoció. Pero no obstante la influencia de Kipling, la de London sobre algunos. de los mismos cuentos tendrá que reconocerse también, por dos razones de peso: una es que tanto el norteamericano como el sudamericano pertenecían a la escuela del naturalismo, no así Kipling; y la segunda, la similitud de trama, temas y motivos, y de la teoría que se deduce de ellos, que se evidencia en la lectura de algunas obras de London y otras de Quiroga.

El naturalismo fue el movimiento que buscaba aplicar teorías y métodos científicos a la literatura. Los naturalistas opinaban que todo lo que hace un ser humano está determinado por la herencia biológica o por el ambiente, o por ambos, y mostraban a este ser atrapado por poderosas fuerzas fuera de su control.

Kipling nunca tuvo esto en su literatura. Horacio Quiroga creó, efectivamente, personajes animales muy semejantes a los del victoriano inglés, pero además dio a sus cuentos de animales la misma teoría naturalista que London había dado a los suyos.

Reconocida por algunos críticos, pero rara vez analizada en detalle, la influencia de London sobre Quiroga puede reconocerse, directa o indirectamente, en los siguientes contactos.

\section{REGRESIÓN DE INSTINTOS}

«Juan Darién» (1924) es un cuento largo de Quiroga que guarda notable semejanza de trama y de intención con la obra más famosa de London, «E1 llamado de la selva» («The Call of the Wild», 1903). Esta última describe las aventuras de Buck, perro doméstico, 1levado al Yukón, donde aprende que sólo puede sobrevivir si se convierte en animal salvaje. Por un tiempo tiene la protección de un amo bondadoso, John Thornton, pero después de que éste es matado por los indios yeehats, Buck retorna con mayor fuerza al primitivismo que ya se había estado gestando dentro de su ser, y termina encabezando una manada de lobos ${ }^{8}$.

En el cuento de Quiroga, Juan Darién es un cachorro de tigre, transformado en un niño por una sabia serpiente y ha sido criado por una mujer solitaria. Al morir su madre, Juan Darién se ve perseguido y hostilizado por el populacho, que sospecha que el muchacho es descendiente

8 Jack London, "The Call of the Wild», en Works of Jack London (Nueva York, Avenel Books, 1980), pp. 15-74. 
de los odiados tigres, terror de todos los pueblos situados al margen de la jungla. Herido y casi quemado vivo por la crueldad de aquellos seres humanos, Juan escapa a la selva, vuelve al primitivo salvajismo que le dicta su alma de tigre, retorna a su forma animal y termina encabezando una manada de tigres?

La teoría naturalista de la novela norteamericana y del cuento sudamericano mencionados está clara: al enfrentarse a una sociedad de seres humanos brutales y al vivir en un medio igualmente primitivo y brutal, las víctimas sienten que se despiertan en ellas instintos salvajes adormecidos por siglos de civilización.

Ambas obras tienen escenas comunes, como la penosa parte en que Buck, el perro-lobo, visita el lugar de entierro de John Thornton, y Juan Darién, la tumba de su madre. Ambos seres humanos representaban en cada historia a las únicas personas que, por el amor, pudieran haber mantenido al perro-lobo y al niño-tigre dentro de la sociedad de seres humanos. Tal es también la parte decisiva en cada obra, en la que el animal ya evolucionado responde al llamado definitivo del instinto salvaje que siempre había morado en lo más recóndito de su alma:

He walked to the center of the open space and listened. It was the call, the many noted call, sounding more luringly and compelling than ever before. And as never before, he was ready to obey. John Thornton was dead. The last tie was broken. Man and the claims of man no longer bound him ${ }^{10}$.

Y retornando a la tumba... arrancóse de un manotazo la venda de la herida, escribió en la cruz con su propia sangre, con grandes caracteres, debajo del nombre de su madre:

$$
\begin{gathered}
\text { Y } \\
\text { JUAN DARIEN }
\end{gathered}
$$

... Y enviando con sus hermanos un rugido de desafío... concluyó:

-Ahora, a la selva. IY tigre para siempre! ${ }^{11}$.

\section{Estudio DE LA AGONÍA}

Tanto Jack London como Horacio Quiroga fueron acusados de haber demostrado a veces un mórbido interés por analizar a los seres hu-

9 Horacio Quiroga, «Juan Darién», en El desierto (Buenos Aires, Casa Losada, 1956), pp. 119-37.

${ }_{10}$ London, op. cit., p. 72.

11 Horacio Quiroga, op. cit., p. 137. 
manos en sus momentos de agonía. Acusación acaso bien fundada, pero ;en ambos aquel interés era genuinamente artístico y los dos autores usaron del tema para presentar a sus personajes atrapados por fuerzas que no podían comprender ni controlar.

El famosísimo cuento de Jack London, «Fuego en la nieve» («To Build a Fire», 1907), estudia con minucioso detalle los últimos momentos de la vida de un hombre próximo a morir de frío. En esos instantes supremos el hombre sólo atina a rememorar y repetirse lo que «un viejo lenguaraz» («an old hoss») le había dicho sobre el terrible invierno ártico. Su muerte inminente es presenciada por su propio perro, el cual, más inteligente que el ser humano mismo, lo abandona para salvarse. Quiroga tiene no uno, sino varios cuentos con tema y final paralelos. «La insolación» (1908), como el cuento londoniano mencionado, presenta también el punto de vista animal, pues algunos perros presienten el momento en que su amo va a desplomarse finalmente, abatido por el fulminante sol del trópico argentino. El paralelo existente entre ambos cuentos recibió un excelente análisis de Arnold Chapman, uno de los pocos buenos trabajos pertenecientes a la magra literatura comparada de Hispanoamérica ${ }^{12}$. También en «A la deriva» (antes de 1917), Quiroga reconstruyó los momentos postreros de un hombre mordido por una serpiente venenosa y que yace en una canoa, preguntándose tan sólo si la última vez que había visto a su patrón había sido un jueves o un viernes ${ }^{13}$. Todavía, en «El hombre muerto» (1926), un colono que por accidente se hiere a sí mismo con un machete, pasa los últimos momentos ofreciéndose pruebas triviales de que no va a morir ${ }^{14}$.

\section{RETORNO A LA PREHISTORIA}

Aún mayor semejanza de argumento y teoría guardan los cuentos «A relic of the Pliocene» (Jack London, 1904) y «El salvaje» (Quiroga, 1920) ${ }^{15}$. En el primero, un cazador se encuentra, inesperadamente, en un valle .... in the direction of the northeast» en compañía de un mamut, último representante del plioceno en la tierra. Se acechan y se persiguen uno al otro hasta que la habilidad de poder pensar del ser hu-

12 Chapman, «Between Fire and Ice...», op. cit.

13 Horacio Quiroga, "A la deriva», en Cuenios de amor, de locura y de muerte (Buenos Aires, Casa Losada, 1964), pp. 65-8.

14 Quiroga, «El hombre muerto», en Cuentos de amor..., op. cit., pp. 69-77.

15 London, «A relic of the Pliocene», en London, op. cit., pp. 483-90; H. Quiroga, «El salvaje», en El salvaje (Buenos Aires, Casa Losada, 1963), pp. 7-14. 
mano inclina la balanza a su favor. En el cuento de Quiroga, uno de sus más famosos, un científico, con una «luz ultrahistórica» en sus ojos, se encuentra compartiendo un valle boscoso con un nothosaurio carnívoro, sobreviviente de alguna edad prehistórica. Ambos se acechan y dan caza hasta que la inteligencia humana permite al cientifico ganar el encuentro decisivo y sobrevivir.

Pero la influencia londoniana muestra haber ido más allá de la sim-ple inspiración o préstamo de tema. Algunas frases del cuento de London parecen haber hallado su eco en el de Quiroga. En ambas historias el matador del monstruo habla con el autor:

1) La afirmación de lo imprevisto:

«That», he said, and said without the slightest of impressiviness, «that came from a mammoth» ${ }^{16}$.

- ¿Qué? - dije por fin.

- Un dinosaurio... un nothosaurio carnívoro.

-Jamás. ¿Usted lo ha visto?

-Sí.

No se le movía una pestaña mientras me miraba ${ }^{17}$.

2) Las leyes anormales de la vida:

«... the oldest breed on earth» 18 .

«... él bajó hasta nuestra edad» ${ }^{19}$.

3) E1 enemigo prehistórico:

«... The mammoth no longer exists. How do I know? I killed the last one with my own right arm» ${ }^{20}$.

El hombre se detuvo.

- ¿Qué pasó? -le dije.

-Nada... Lo maté.

-Al... ¿dinosaurio?

-Sí, a él... El era un dinosaurio... un nothosaurio carnívoro... y tenía un olor pestilente de fiera. ¿Comprende ahora? ${ }^{21 .}$

16 London, «A relic...», op. cit., p. 485.

17 Quiroga, «El salvaje», op. cit., p. 9.

18 London, loc. cit., p. 490.

19 Quiroga, loc. cit.

20 London, "A relic...», op. cit., p. 485.

21 Quiroga, «El salvaje», op. cit., p. 12. 
4) Regresión:

My clothes went to rags and tatters, but I never stopped to mend til at last I ran naked as a son of the earth, with nothing but the old hand axe in one hand and a cobble in the other ${ }^{22}$.

... no tenía ropa, y sí pelo en todo el cuerpo. En una palabra, había regresado a las eras pasadas... ${ }^{23}$.

5) Una misma roca o peñón:

... High up on one side was one of those big pivot rocks or balancing rocks, as some call them, weighing all of a couple of hundred tons. Just the thing... the old boulder tilted up lazily and dropped into place... ${ }^{24}$.

De allí surgió mi plan de defensa. En guardia siempre, siguiendo al dinosaurio en su girar, tuve tiempo de descender diez metros y desprender una gran esquirla de la rajadura central, con la que volví a la cumbre. Y hundiéndola como cuña en la grieta, hice palanca y sentí contra mi pecho la conmoción del peñasco a punto de precipitarse...

En un instante cargué sobre la palanca mi peso y... el inmenso peñasco cayó... ${ }^{25}$.

6) El lugar de ejecución del monstruo:

"And where is this valley?» I asked.

He waved his hand in the direction of the northeast... ${ }^{26}$.

-E1 cantil... ¿es ése? -pregunté a mi hombre.

El volvió la cabeza y miró largo rato el peñón que iba blanqueando tras la lluvia.

-Sí -repuso al fin con la vista fija en él ${ }^{27}$.

Como sencilla conclusión para ambos cuentos, cada uno tratado a su manera por tan originales narradores, bien podemos citar las palabras que Mary Kay Dodson usó para referirse a Buck, el perro-lobo, y que ahora podemos aplicar a ambos hombres modernos que se vieron forzados a retroceder a las eras prehistóricas:

... his heredity and environment forced him to kill or to be killed... His imagination helped him not only to survive, but also to adapt ${ }^{28}$.

22 London, "A relic...», op. cit., p. 489.

23 Quiroga, «El salvaje», op. cit., p. 11.

24 London, «A relic...», op. cit., p. 488.

${ }_{25}$ Quiroga, «E1 salvaje», op. cit., p. 13.

26 London, «A relic...», op. cit., p. 490.

27 Quiroga, «El salvaje», op. cit., p. 14.

28 Mary K. Dodson, "Naturalism in the works of Jack London», The Jack London Newsleter, 4, 3 (1971), pp. 130-9; cita en p. 132. 
La mayor parte de los estudios de literatura comparada pertenecen al campo de las suposiciones. En el caso de la influencia de Jack London sobre Horacio Quiroga se podría ofrecer, acaso, bien comprobada información que establece que la primera obra de London traducida al castellano no lo fue sino hasta 1925, años después de que hubieran aparecido los cuentos de Quiroga ya mencionados ${ }^{29}$. Pero también se podría responder a esto que nada pudo haber impedido que la literatura de London hubiera 1legado por otra vía a Quiroga, como también al resto de los narradores hispanoamericanos: en su forma original en inglés, o en traducciones del francés o aun en simple intercambio o conversación con artistas compatriotas o extranjeros que la pudieron haber leído o conocido de oídas. Recuérdese que Buenos Aires y Montevideo, las capitales intelectuales de Quiroga, son precisamente las dos ciudades hispanoamericanas más abiertas a las innovaciones y corrientes provenientes del extranjero, especialmente del Viejo Mundo. $Y$ ya por siglos existe y ha existido en el mundo hispánico aquella honrosa institución de la «tertulia», círculo intelectual en el que se comparten ideas, temas y estilos, ya sean nacionales o extranjeros. Basta tomar cualquier biografía ilustrada de Horacio Quiroga para admirar fotos de él en tertulia con sus colegas y amigos del Buenos Aires cosmopolita ${ }^{30}$.

Sin duda que en el futuro los comparatistas descubrirán la existencia de otros motivos y temas londonianos en la cuentística de Horacio Quiroga. Tarea nada fácil, considerando que ambos autores se caracterizaron por una producción literaria sumamente abundante. Además, un estudio comparativo de esta clase necesitará de una detallada investigación de los rasgos biográficos que fueron comunes a los dos narradores. Ambos, el norteamericano y el sudamericano, trabajaron y lucharon en contacto con una naturaleza salvaje y, a menudo, brutal. Ambos alternaron también la vida a campo abierto con la amistad de gente de letras de ciudades cosmopolitas. Ambos demostraron igual interés por seres fuertes, impulsados por instintos primitivos, en constante lucha por la supervivencia. Ambos, aventureros y artistas como fueron, reflejaron la experiencia del propio vivir en sus admirables cuentos. $\mathrm{Y}$ ambos encontraron el mismo fin que una vez crearon para algunos de sus propios vigorosos personajes.

29 Chapman, The Spanish American..., op. cit., p. 205.

30 Emir Rodríguez Monegal, Genio y figura de Horacio Quiroga (Buenos Aires, Editorial Universitaria de Buenos Aires, 1967), pp. 76 y 93. 